\title{
Analysis of Failure Characteristics and Strength Criterion of Coal-Rock Combined Body with Different Height Ratios
}

\author{
Tuo Wang $\mathbb{D},{ }^{1}$ Zhanguo Ma $\mathbb{D},{ }^{1,2}$ Peng Gong $\mathbb{D},{ }^{1}$ Ning $L i \mathbb{D},{ }^{1}$ and Shixing Cheng $\mathbb{D}^{1}$ \\ ${ }^{1}$ State Key Laboratory for Geomechanics and Deep Underground Engineering, China University of Mining \& Technology, \\ Xuzhou 221116, China \\ ${ }^{2}$ School of Mechanics and Civil Engineering, China University of Mining \& Technology, Xuzhou 221116, China
}

Correspondence should be addressed to Zhanguo Ma; 1044@cumt.edu.cn

Received 18 May 2020; Revised 19 June 2020; Accepted 29 June 2020; Published 10 August 2020

Academic Editor: Zhiqiang Yin

Copyright (C) 2020 Tuo Wang et al. This is an open access article distributed under the Creative Commons Attribution License, which permits unrestricted use, distribution, and reproduction in any medium, provided the original work is properly cited.

\begin{abstract}
In underground mining and roadway support engineering of coal mine, the coal and rock layers bear loads together; therefore, the deformation and mechanical characteristics of the coal-rock combined bodies are not the same as those of the pure coal or rock bodies. In this paper, conventional triaxial compression tests of coal-rock combined bodies with different height ratios were conducted. And the stress and deformation characteristics of coal-rock combined body were studied and the experimental results were analyzed with different strength criteria. The results show that the peak stress, elastic modulus, and strength reduction coefficient of coal-rock combined body are negatively correlated with the ratio of coal to coal-rock combination height and positively correlated with the confining pressure; the coal-rock combination shows obvious ductility under $10 \mathrm{MPa}$ confining pressure. Under the conventional triaxial condition, the shear failure was the main cause of the lateral deformation of the coal body in the coal-rock combination, which was much larger than that of the rock body. The circle deformation value, volume strain value, and the deformation rate in the postpeak stage of coal-rock combination are much higher than those in the prepeak stage. Mohr-Coulomb and general Hoek-Brown strength criterion fit the experimental results well.
\end{abstract}

\section{Introduction}

With the continuous development and improvement of roadway support technology and theory, more and more mines choose to arrange the roadway in the coal seam to reduce the amount of rock roadway excavation. In order to maintain good roof conditions, for roadways with low coal seam strength, the roadways are generally arranged along the roof of the coal seam. Also for the mining of thin coal seams, the side of the roadway is often in the state of half coal seam and half rock. The roadway driving along the roof is shown in Figure 1(a) and the semicoal-rock roadway in Figure 1(b).

The common features of these two types of roadways are that the coal seam and roof rock of the roadway are weakly adhered. The strength of the coal body is low, and the coal seam is prone to large deformation under the action of vertical pressure. The coal seam is liable to slip and deform along the weak side of the coal-rock interface toward the roadway, causing a large series of deformation and shrinkage and then a series of deformation failure modes such as roof sinking and floor bulging [1-7].

Many experts and scholars have done tests on the mechanical properties of coal and rock masses, including conventional triaxial tests and true triaxial tests on pure coal and rock masses and experiments on rock mechanical properties under different stress paths [8-17]. However, in the underground engineering, the overburden load is carried by the coal body and the rock mass together, and the safety and stability of the roadway are determined by the roof rock and coal mass. Therefore, the deformation and failure characteristics of a single coal or rock mass cannot accurately describe the deformation and stress characteristics of such a roadway.

In recent years, some experts have studied the mechanical properties of coal-rock combined samples under different loads and obtained the precursor characteristics and acoustic emission information of failure of coal-rock 


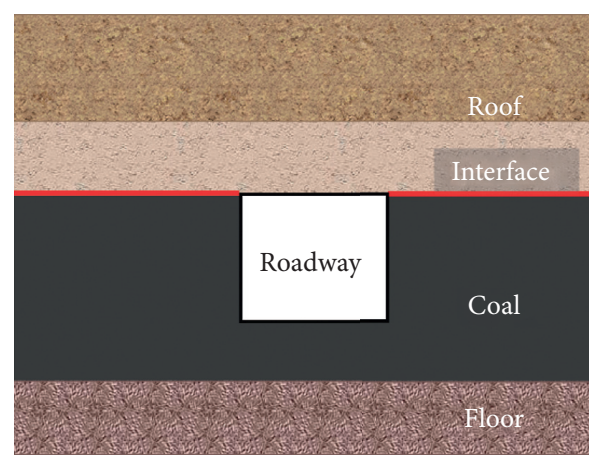

(a)

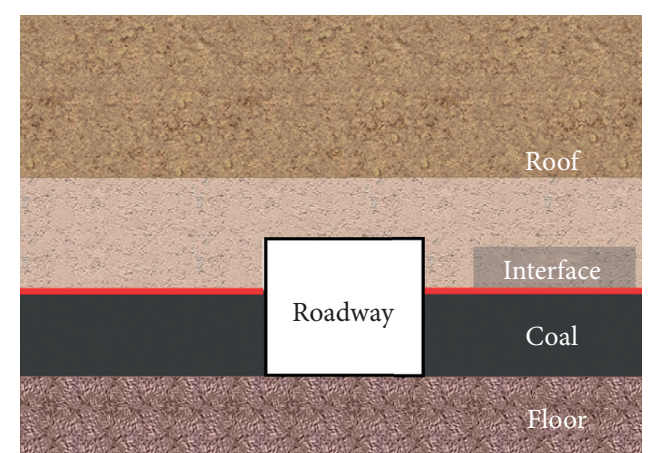

(b)

FIgURe 1: Two types of roadways. (a) Roadway driving along the roof. (b) Semicoal-rock roadway.

combined samples through experiments [18-26]. Zuo $[27,28]$ studied the failure behavior and strength characteristics of coal and rock masses in equal proportions, with confining pressure as a variable. Tan [29] determined the mechanical properties of coal-rock combined samples and obtained a new approach considering the influences of roof and/or floor which was proposed to evaluate the impact capability of coal seam. Huang [30] performed uniaxial compression tests on composite coal rocks under different loading rates and analyzed the effects of loading and unloading rates and paths on the mechanical properties of combined coal and rocks. Lu [31] proposed a method to reduce the impact tendency by weakening the strength of the coal-rock combined body based on the experimental results. Wang [32], in order to understand the sliding mechanism between coal and rock, studied the unstable sliding conditions of coal and rock samples, sliding types under different conditions, displacement evolution law, and AE characteristics through the sliding test between coal and rock. Li [21] used a direct shear test under constant positive load conditions to study the shear characteristics of the natural coalrock interface and analyze the acoustic emission signals during the shear process. However, their research is based on the proportion of coal and rock, and there is a little research on the different proportion of coal height to the total height of coal-rock combined samples.

At present, many scholars have developed a variety of strength criteria based on conventional triaxial compression test data, such as Hoek [33, 34], You [35], Zuo [36], and Peng [35]. These strength criteria show good applicability and are widely used in the failure of rock structure. Based on the different thickness ratios of coal seams and roofs under different geological conditions, this paper conducted a laboratory test on the mechanical properties of coal-rock combined samples with different height ratios of coal and rock samples. The relationship between the different height ratios on the peak strength, elastic modulus, and strength reduction coefficient of coal-rock combined samples was analyzed. The strength of coal-rock combination is verified and analyzed by using the strength criterion and briefly describes the reasons for the lateral deformation of the coalrock combination which provides a theoretical and experimental basis for understanding the characteristics of deformation, failure, and failure of surrounding rock in roadway driving along the roof and the semicoal-rock roadway with different coal seam roof thickness ratios.

\section{Experiment}

2.1. Samples Preparation. The coal and rock samples of the coal-rock combined bodies were taken directly from number 3 coal seam of Zhangcun Coal Mine, Shanxi Province, China. During the transportation process, the samples are sealed with cling film to reduce water loss and reduce the degree of weathering and transport them back to the laboratory for core processing in a timely manner.

Coal and rock samples are processed to different heights, and the processing accuracy meets the requirements of the test method. After the processing was completed, the rock samples with obvious natural fissures were selected and removed, and then the RSM-SY5 (N) digital intelligent ultrasonic instrument was used to detect and select the interior of the rock. Figure 2(a) shows rock samples with good integrity and uniformity. Due to the long-term high temperature and high-pressure conditions during the formation of coal, the coal seam has a certain degree of cohesive force with the direct roof and is not a nonbonded free mode. Therefore, in the experiments, the medium-viscosity white latex was used as an adhesive to bond the coal and rock bodies and the adhesive (see Figure 2(b)). The adhesive should be coated as thin as possible and ensure uniformity (see Figure 2(c)). After the bond was completed, the coal-rock combined samples were numbered and weighed. The numbering was performed according to the following principles, such as the number RCB-1-3-1, the number " $\mathrm{R}$ " represents rock, "C" represents coal, "B" represents the form of bonding between coal-rock combined samples, "1-3" represents the height ratio of rock, coal is $1: 3$, and the last " 1 " represents sample number 1 in this group (see Figure 2(d)).

The dimensions of coal-rock combined samples were performed in accordance with the standard size of the International Rock Mechanics Society [37]. The total height of the coal and rock specimens is $100 \mathrm{~mm}$ and the diameter is $50 \mathrm{~mm}$. Before the test, the diameter, height, and weight of the coal and the rock body were measured individually and combined. Table 1 shows the measurement results. 


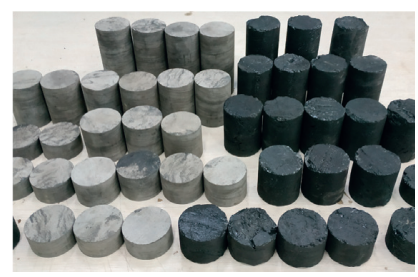

(a)

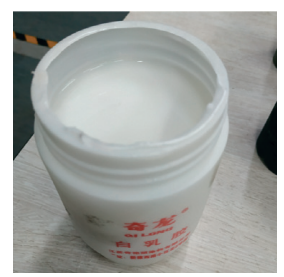

(b)

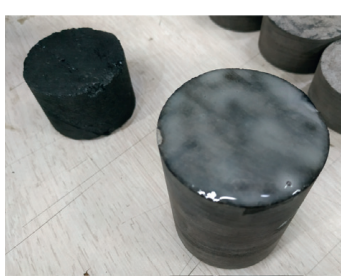

(c)

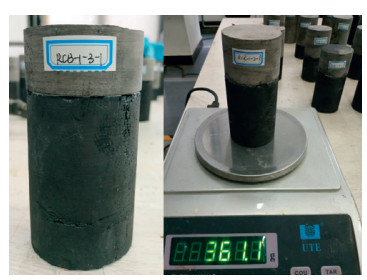

(d)

Figure 2: Coal and rock combined body manufacturing process. (a) Coal and rock samples. (b) White latex adhesive. (c) The adhesive applied to the interface. (d) Samples labeling and weighing.

TABLE 1: Grouping of coal-rock combined samples and their basic parameters.

\begin{tabular}{|c|c|c|c|c|c|c|c|c|c|}
\hline \multirow[t]{2}{*}{ Specimen number } & \multicolumn{2}{|c|}{$\begin{array}{l}\text { Diameter } \\
(\mathrm{mm})\end{array}$} & \multicolumn{3}{|c|}{ Height (mm) } & \multicolumn{2}{|c|}{ Weight $(\mathrm{g})$} & \multirow[t]{2}{*}{ Confining pressure $(\mathrm{MPa})$} & \multirow[t]{2}{*}{ Density $\rho / \mathrm{g} \cdot \mathrm{cm}^{-3}$} \\
\hline & $D_{r}$ & $D_{c}$ & $H_{r}$ & $H_{c}$ & $H_{t}$ & $m_{r}$ & $m_{c}$ & & \\
\hline Rock & 50.09 & & 100.79 & & & 544.75 & & 0 & 2.744 \\
\hline Rock & 50.16 & & 101.83 & & & 547.25 & & 5 & 2.720 \\
\hline Rock & 50.18 & & 101.88 & & & 541.45 & & 10 & 2.688 \\
\hline Coal & & 50.06 & & 100.60 & & & 275.25 & 0 & 1.390 \\
\hline Coal & & 50.05 & & 102.07 & & & 277.30 & 5 & 1.381 \\
\hline Coal & & 50.15 & & 102.56 & & & 280.40 & 10 & 1.384 \\
\hline RCB-2-1 & 50.12 & 50.09 & 66.81 & 33.99 & 100.99 & 90.25 & 360.10 & 0 & 2.254 \\
\hline RCB-2-1 & 50.11 & 50.14 & 66.90 & 34.46 & 101.65 & 92.03 & 360.47 & 5 & 2.256 \\
\hline RCB-2-1 & 50.02 & 50.14 & 66.82 & 34.01 & 101.07 & 89.53 & 356.67 & 10 & 2.241 \\
\hline RCB-1-1 & 50.14 & 50.19 & 49.90 & 51.63 & 101.65 & 133.45 & 265.50 & 0 & 1.985 \\
\hline RCB-1-1 & 50.14 & 50.13 & 49.99 & 51.16 & 101.34 & 132.63 & 265.13 & 5 & 1.988 \\
\hline RCB-1-1 & 49.95 & 50.16 & 51.71 & 49.76 & 101.86 & 136.53 & 256.60 & 10 & 1.962 \\
\hline RCB-1-2 & 50.03 & 50.12 & 34.58 & 65.93 & 100.7 & 175.10 & 181.65 & 0 & 1.803 \\
\hline RCB-1-2 & 50.03 & 50.06 & 34.44 & 66 & 100.61 & 176.50 & 180.57 & 5 & 1.804 \\
\hline RCB-1-2 & 50.04 & 50.09 & 34.22 & 65.87 & 100.31 & 178.23 & 181.67 & 10 & 1.822 \\
\hline RCB-1-3 & 49.91 & 50.07 & 25.55 & 75.73 & 101.41 & 200.30 & 130.05 & 0 & 1.659 \\
\hline RCB-1-3 & 49.91 & 50.07 & 25.55 & 75.73 & 101.49 & 200.30 & 130.05 & 5 & 1.659 \\
\hline RCB-1-3 & 50.12 & 50.12 & 24.88 & 76.94 & 102.2 & 205.00 & 135.25 & 10 & 1.688 \\
\hline
\end{tabular}

$D_{r}$ and $D_{c}$ represent the diameter of the rock and coal body, $H_{r}$ and $H_{c}$ represent the height of the rock and coal body, $H_{t}$ represents the height of the coal-rock combination, $m_{r}$ and $m_{c}$ represent the mass of the rock and coal body, and $\rho$ is the coal-rock combined body density. The density of coal body is between 1.378 and $1.39 \mathrm{~g} \mathrm{~cm}^{-3}$, the average density is $1.383 \mathrm{~g} \mathrm{~cm}^{-3}$, the density of rock body is between 2.685 and $2.736 \mathrm{~g} \mathrm{~cm}^{-3}$, and the average density is $2.704 \mathrm{~g} \mathrm{~cm}^{-3}$, and the average density of coal-rock combined body is between coal and rock samples.

2.2. Test Procedure. The tests were divided into uniaxial tests and conventional triaxial tests. The samples include coal and rock samples and coal-rock combined samples. There are four groups of coal-rock combined samples with different height ratios. In the conventional triaxial test, there are six specimens in each group, and the confining pressure is $5 \mathrm{MPa}$ and $10 \mathrm{MPa}$. The uniaxial tests include two specimens in each group. The experimental results excluded the data with large differences, and the remaining two groups of data were averaged. The test was completed on the MTS815.02 electrohydraulic servo rock mechanics test equipment of
China University of Mining and Technology. The equipment of MTS815.02 is shown in Figure 3.

In order to reduce the friction effect of the indenter on the end of the test piece in the conventional triaxial test, according to the research results of J. F. Labuz and Feng [38], this article used a mixture of vaseline and stearic acid to reduce the friction effect of the two ends of the sample. The test steps are as follows:

Step 1: firstly apply petroleum jelly to both ends of the samples, wrap the test piece with a thin heat shrinkable film, place the wrapped test piece on a gasket, then wrap the two layers with a heat shrinkable film, and use 20 \# ethylene-propylene self-adhesive tape to wind it evenly to prevent the oil from seeping in.

Step 2: place the sample in the center of the test bench, use the force control mode, and preload $1 \mathrm{kN}$ force to fix the sample.

Step 3: install the hoop extensometer and drop the triaxial cell.

Step 4: load the confining pressure to a predetermined value at a loading rate of $0.1 \mathrm{MPa} / \mathrm{min}$. 


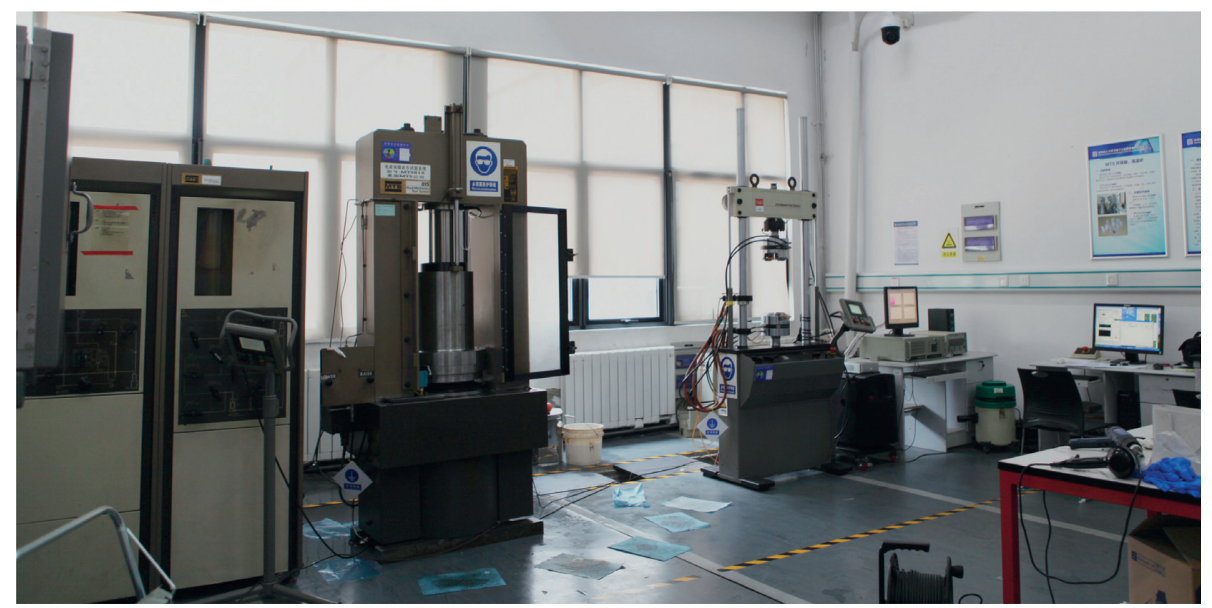

FIGURE 3: MTS815.02 electrohydraulic servo rock mechanics test system.

Step 5: load the axial pressure and use the displacement control mode until the sample was broken. The loading rate was $0.003 \mathrm{~mm} / \mathrm{s}$.

The stress loading path of a conventional triaxial test is shown in Figure 4.

\section{Experimental Results}

3.1. Stress-Strain Characteristics. Pure coal and pure rock samples were subjected to uniaxial compression and conventional triaxial compression tests with confining pressures of $5 \mathrm{MPa}$ and $10 \mathrm{MPa}$. The stress-strain curves of the samples are shown in Figure 5.

Under uniaxial compression, the peak stress of coal samples is $6.38 \mathrm{MPa}$, while that of rock samples is $53.32 \mathrm{MPa}$. Under $5 \mathrm{MPa}$ confining pressure, the peak stress of pure coal samples is $10.03 \mathrm{MPa}$, and that of pure rock samples is $66.2 \mathrm{MPa}$. Under the confining pressure of $10 \mathrm{MPa}$, the stress peak of the pure coal samples is 17.12 $\mathrm{MPa}$, and that of the pure rock samples is $90.94 \mathrm{MPa}$. The stress-strain relationship between coal and rock has a tendency to sink under uniaxial conditions, indicating that coal and rock have obvious crack compaction stages, and the pressure drops rapidly after the peak of the intensity, and the residual strength is almost zero (see Figure 5). After the confining pressure is loaded, due to the low strength of the coal bodies, there is almost no crack compaction stage, the rock strength is high, and the crack compaction stage is not obvious. The coal and rock masses have obvious postpeak softening stages and have the characteristics of ductile failure.

The stress-strain relationship of coal-rock combination under conventional triaxial compression conditions is shown in Figure 6.

The stress-strain curve of coal-rock combination under uniaxial loading condition can be divided into four parts (see Figure 6(a)):

(1) Fracture compaction stage: at this stage, the cracks in the coal-rock combined body and the gaps between the coal and rock were compressed and closed.
Because of the existence of the coal-rock interface and the natural cracks in the samples, the coal-rock combined bodies were initially loaded. The strain growth speed increases at the stage, and the stress increases at a slower rate, so the curve at this stage shows a downward trend.

(2) Elastic phase: at this stage, the internal cracks of the coal-rock combination were closed, and the stress and strain were in a linear relationship.

(3) Yielding stage: at this stage, the stress of the coal-rock combination reached the yield load, internal cracks were initiated, and cracks expanded.

(4) Uninstall phase: at this stage, the internal cracks of the coal-rock combination penetrated, and the stress suddenly dropped. The curve of the coal-rock combination after the peak unloading trend fell below $90^{\circ}$.

The conventional triaxial test preloaded $5 \mathrm{MPa}$ and $10 \mathrm{MPa}$ confining pressure on coal-rock combination. So the fracture compaction stage of the coal-rock combination is not obvious, but there are obvious elastic stage, yield stage, and postpeak softening stage. The peak stress of sample RCB-1-3 is the lowest, and the peak stress of RCB-21 is the highest (see Figures 6(b) and 6(d)). Increasing the pressure of surrounding rock has a significant effect on the strength of the combination, and the peak stress and the postpeak residual intensity value are significantly increased. The strength of coal-rock combined bodies with different height ratios increases, and the rate of stress drop after peaks increases accordingly. The coal-rock combined samples of different combined form are classified, and the coefficient $\delta$ value is introduced to express the percentage of coal height in the height of coal-rock assemblage, which is expressed as

$$
\delta=\frac{h_{\mathrm{ci}}}{h_{M}},
$$

where $h_{\mathrm{ci}}$ is the height of the coal body in the coal-rock complex and $h_{M}$ is the total height of the coal-rock body. 


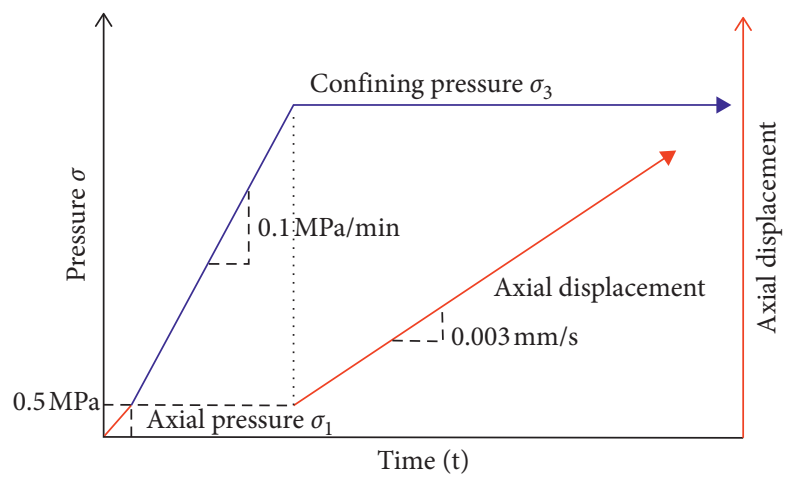

FIgURE 4: Stress loading path of the conventional triaxial test.

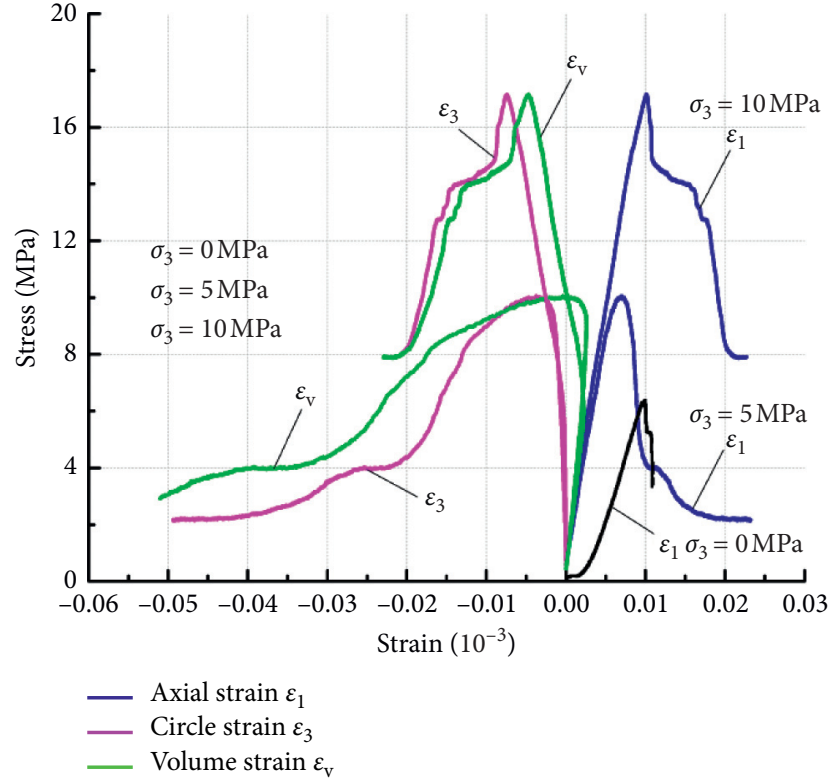

(a)

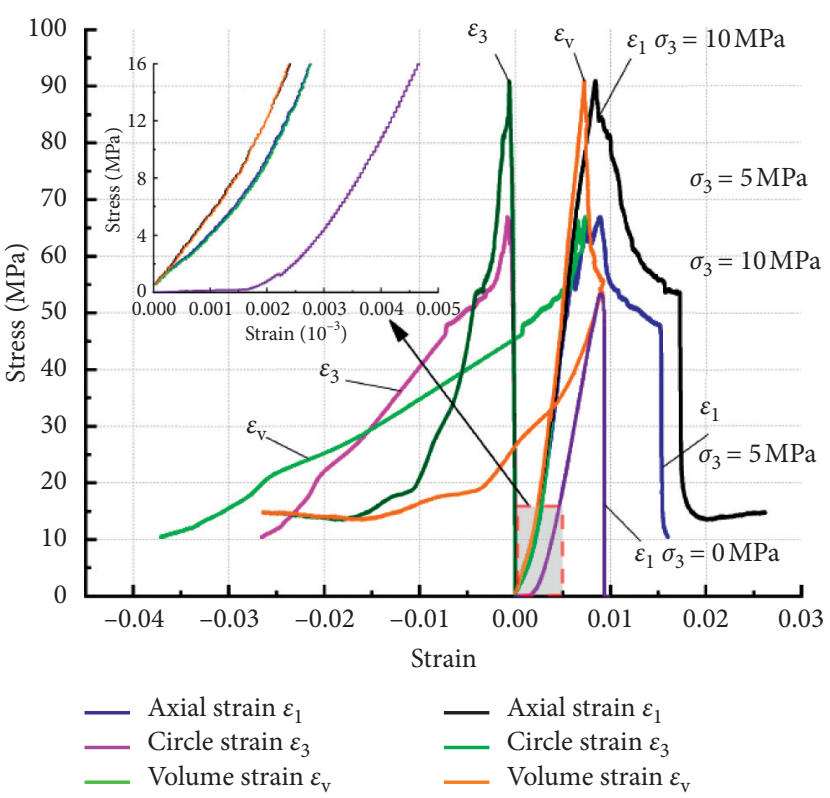

(b)

Figure 5: Stress-strain curves of (a) pure coal samples and (b) pure rock samples under different confining pressures.

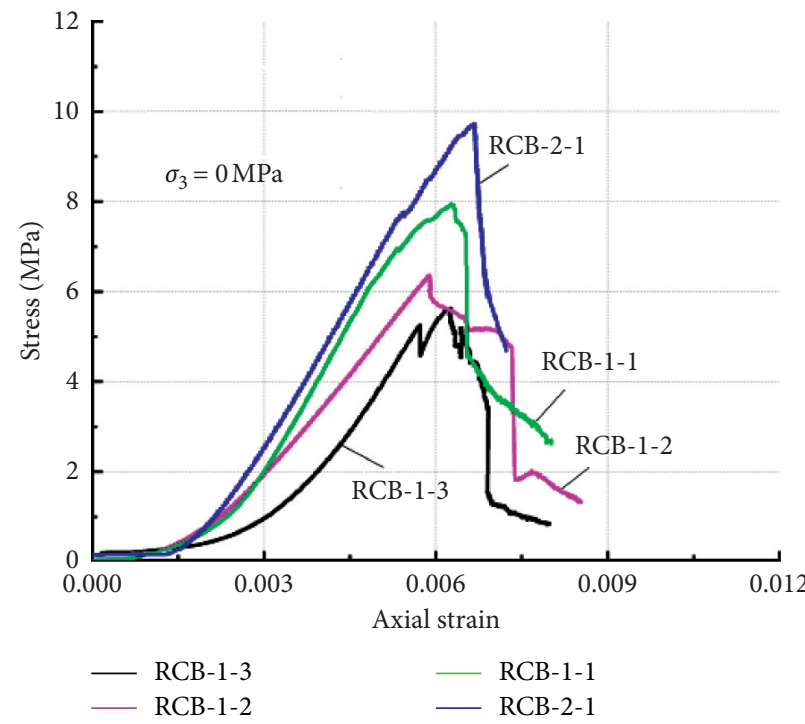

(a)

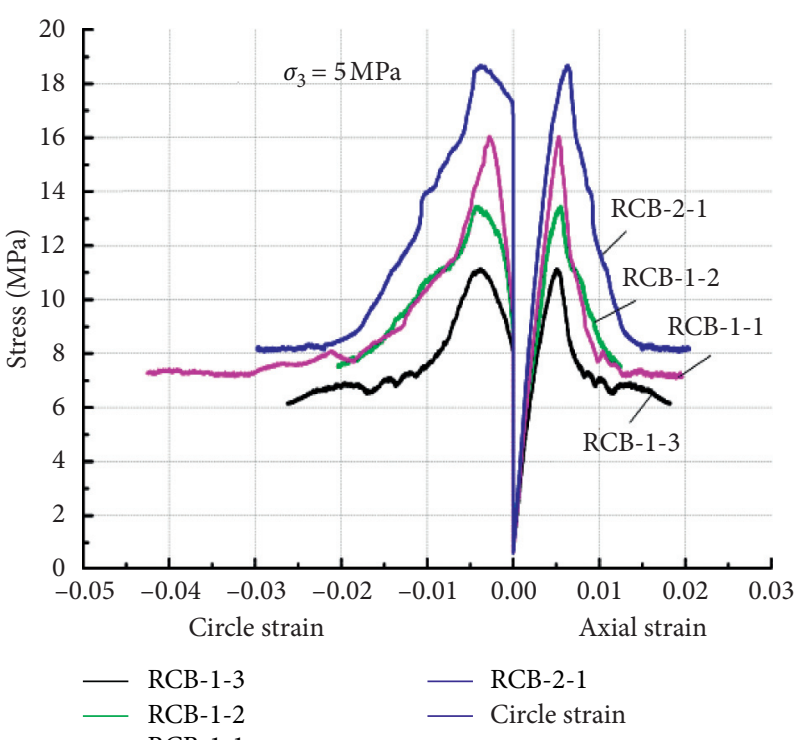

(b)

FIgURE 6: Continued. 


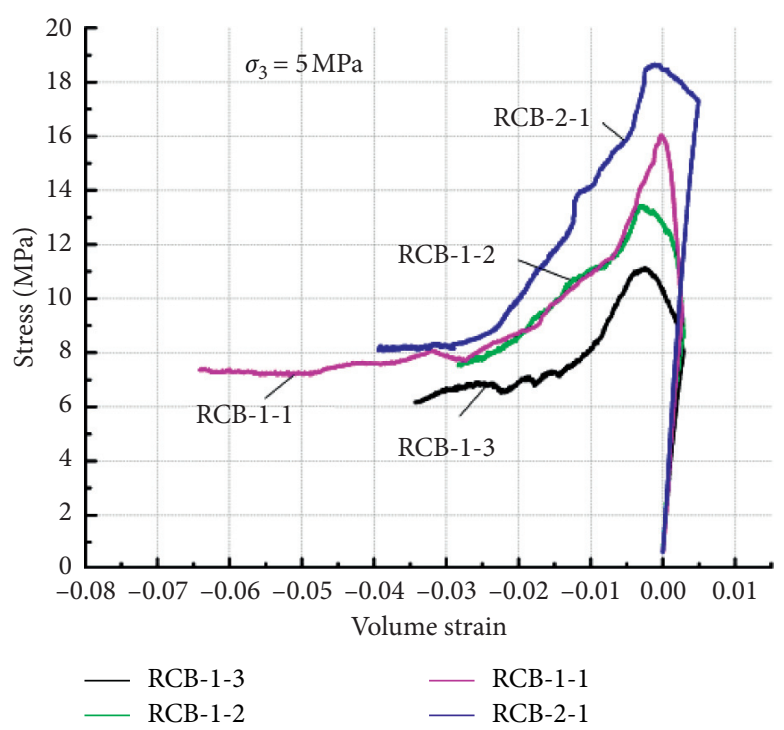

(c)

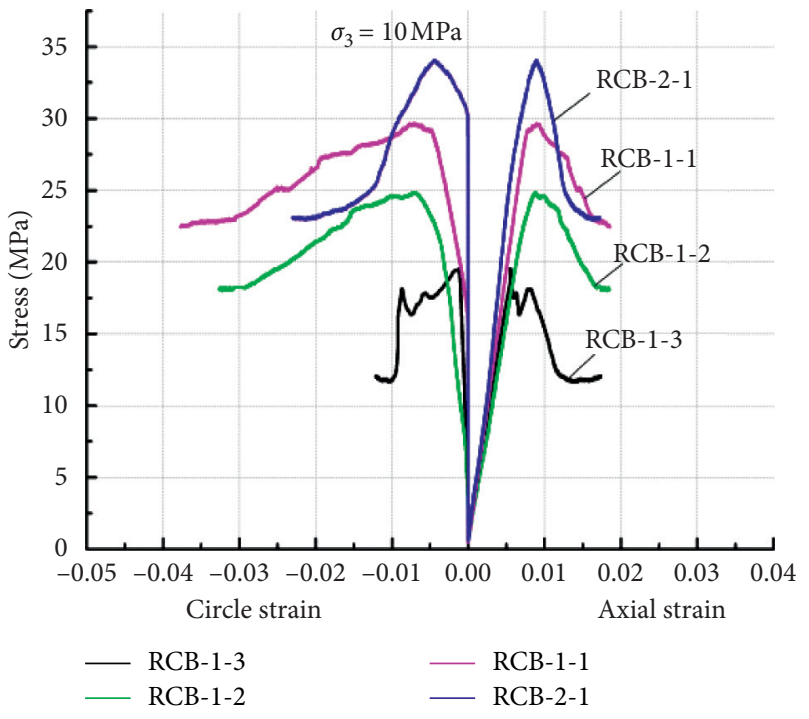

(d)
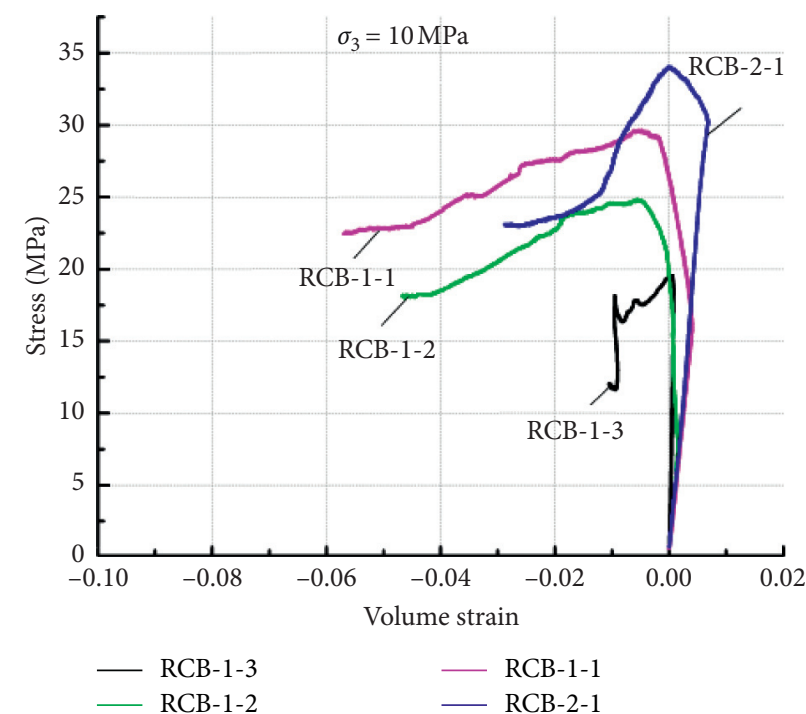

(e)

Figure 6: Axial stress-strain curve of coal-rock combination. (a) Axial strain of coal-rock combination under uniaxial loading. (b, c) The axial and circumferential strains and volume strains of coal-rock combined samples when the confining pressure is $5 \mathrm{MPa}$. (d, e) The axial and circumferential strains and volume strains of coal-rock combined samples when the confining pressure is $10 \mathrm{MPa}$.

The peak strength and axial strain, elastic modulus, circle strain, and volume strain of the test block are shown in Table 2. The uniaxial test only counts the axial strain.

The stress peak of coal-rock combination increases with the increase of confining pressure (see Figure 7(a)). Under the same confining pressure, the peak stress of the coal-rock combination is the greatest when $\delta=0.33$, the strength decreases with the increase of the value of $\delta$, and the peak stress is the smallest when $\delta=0.75$. The peak stress of coal and rock samples and coal-rock combination increased with the increase of confining pressure. The peak stress of coal rock pure samples and coal rock combination is positively correlated with surrounding rock pressure. With the surrounding rock pressure from $0 \mathrm{MPa}$ to $5 \mathrm{MPa}$, the change proportion of the pressure is basically smaller than that of the surrounding rock pressure from $5 \mathrm{MPa}$ to $10 \mathrm{MPa}$. The change ratio of rock is the smallest, which is less than 0.4. The change ratio of coal-rock combination is more than 0.7 , and the maximum value is 1.1 , which indicates that the surrounding rock pressure has an obvious influence on the peak strength (see Figure 7(b)).

According to the research by Yang and Liu $[39,40]$, it can be known that when the diameter of the rock is the same, as the height increases, the strength of the rock gradually decreases and finally tends to a fixed value. Therefore, it can be concluded that when $\delta$ decreases gradually, the strength of the coal body with smaller strength in the combination increases gradually, and the peak strength of the coal-rock combined samples increases, which proves that the experimental results are reasonable. 
TABLE 2: Test results of coal and rock pure samples and coal-rock combined samples.

\begin{tabular}{|c|c|c|c|c|c|c|c|c|}
\hline Samples & $\delta$ & $\begin{array}{c}\sigma_{3} \\
(\mathrm{MPa})\end{array}$ & $\begin{array}{c}\text { Elastic modulus } \\
(\mathrm{GPa})\end{array}$ & $\begin{array}{c}\text { Peak stress } \\
(\mathrm{MPa})\end{array}$ & $\begin{array}{l}\text { Residual strength } \\
(\mathrm{MPa})\end{array}$ & $\begin{array}{c}\text { Axial strain } \\
\left(10^{-3}\right)\end{array}$ & $\begin{array}{l}\text { Circle strain } \\
\left(10^{-3}\right)\end{array}$ & Volume strain $\left(10^{-3}\right)$ \\
\hline \multirow{4}{*}{ ROCK } & \multirow{4}{*}{0} & 0 & 6.88 & 53.32 & 0.85 & 9.04 & & \\
\hline & & 5 & 7.7 & 66.20 & 6.32 & 8.93 & -0.79 & 7.35 \\
\hline & & 10 & 9.11 & 90.93 & 14.71 & 8.44 & -0.59 & 7.26 \\
\hline & & 0 & 1.44 & 5.61 & 0.75 & 6.22 & & \\
\hline \multirow[t]{3}{*}{ RCB-1-3 } & \multirow[t]{3}{*}{0.75} & 5 & 3.37 & 10.9 & 6.51 & 5.06 & -3.74 & -2.42 \\
\hline & & 10 & 3.74 & 18.71 & 12.09 & 7.79 & -8.64 & -9.49 \\
\hline & & 0 & 1.54 & 6.36 & 1.23 & 5.89 & & \\
\hline \multirow[t]{3}{*}{ RCB-1-2 } & \multirow[t]{3}{*}{0.67} & 5 & 3.38 & 12.33 & 7.02 & 5.55 & -4.35 & -3.15 \\
\hline & & 10 & 3.52 & 24.57 & 18.08 & 8.83 & -7.14 & -5.45 \\
\hline & & 0 & 2.48 & 7.93 & 1.95 & 6.27 & & \\
\hline \multirow[t]{3}{*}{ RCB-1-1 } & \multirow[t]{3}{*}{0.5} & 5 & 3.58 & 14.12 & 7.20 & 5.28 & -2.67 & -0.06 \\
\hline & & 10 & 3.89 & 29.51 & 22.7 & 9.05 & -7.1 & -5.15 \\
\hline & & 0 & 2.19 & 9.72 & 1.21 & 6.68 & & \\
\hline \multirow[t]{3}{*}{ RCB-2-1 } & \multirow[t]{3}{*}{0.33} & 5 & 4.48 & 17.92 & 8.13 & 6.32 & -3.9 & -1.48 \\
\hline & & 10 & 4.63 & 33.92 & 23.32 & 8.92 & -6.41 & -3.9 \\
\hline & & 0 & 1.22 & 6.38 & 1.8 & 7.98 & & \\
\hline \multirow[t]{2}{*}{ Coal } & \multirow[t]{2}{*}{1} & 5 & 2.07 & 10.03 & 2.21 & 6.88 & -3.33 & 0.22 \\
\hline & & 10 & 2.29 & 17.1 & 7.85 & 9.39 & -7.58 & -5.77 \\
\hline
\end{tabular}

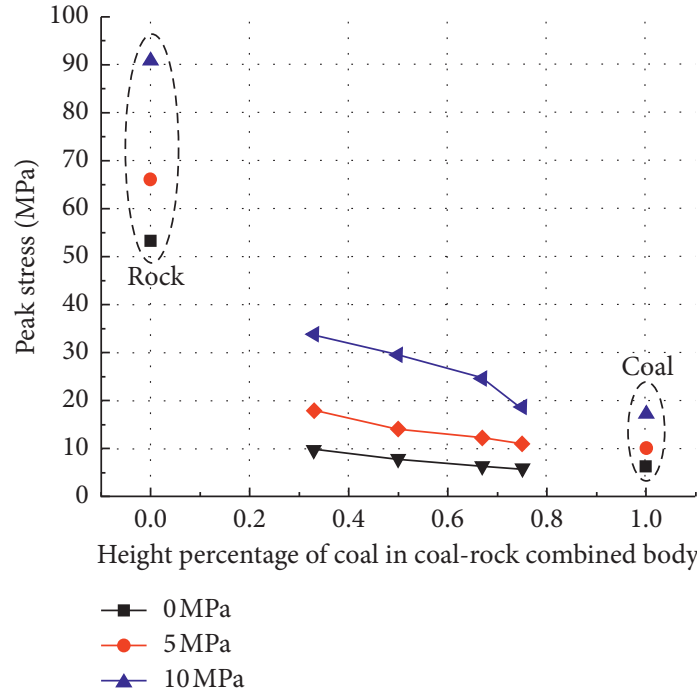

(a)

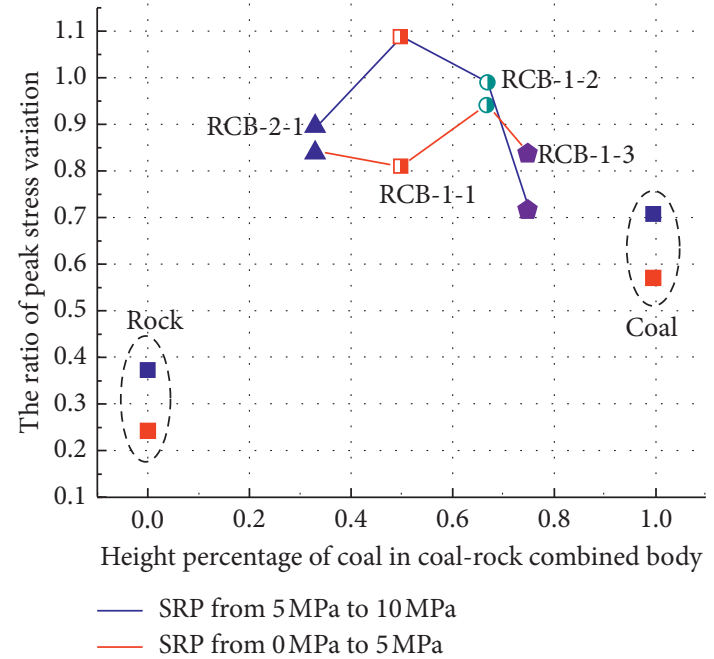

(b)

FigURE 7: The relationship between the peak stress and its change value of coal-rock combination with $\delta$ under different confining pressures. (a) Changes in stress peaks with $\delta$. (b) Changes in stress peaks at confining pressures from $0 \mathrm{MPa}$ to $5 \mathrm{MPa}$ and $5 \mathrm{MPa}$ to $10 \mathrm{MPa}$.

For the coal-rock combined samples under uniaxial compression, due to the process of compaction of coal and rock interface at the initial stage, the axial strain is relatively large. Therefore, the actual axial strain of coal-rock combined samples should be the strain that removing the interface of the compressed coal-rock combination, the calculation is shown in

$$
\varepsilon_{1}^{\prime}=\varepsilon_{1}-\frac{H_{t}-H_{c}-H_{r}}{H_{t}},
$$

where $\varepsilon_{1}^{\prime}$ is the actual axial strain of the coal-rock combination, $\varepsilon_{1}$ is the axial strain obtained from the test, $H_{\mathrm{t}}$ is the height of the coal-rock combination containing the interface, $H_{\mathrm{r}}$ is the height of the rock sample, and $H_{\mathrm{c}}$ is the height of the coal sample. The measured height values have been calculated in Table 1 .

The peak strain of the rock is the highest when the confining pressure is $0 \mathrm{MPa}$, and the peak strain of coal changes little under the confining pressures of $0 \mathrm{MPa}$ and $5 \mathrm{MPa}$ (see Figure 8). When the confining pressure reaches $10 \mathrm{MPa}$, the peak strain value increases greatly. The difference in peak strain is caused by the respective strengths of coal and rock samples. The uniaxial peak stress of the rock exceeds $50 \mathrm{MPa}$. Under the confining pressure of $10 \mathrm{MPa}$, the ductility characteristics of the rock are not obvious. On the contrary, the coal body has better ductility. When the 


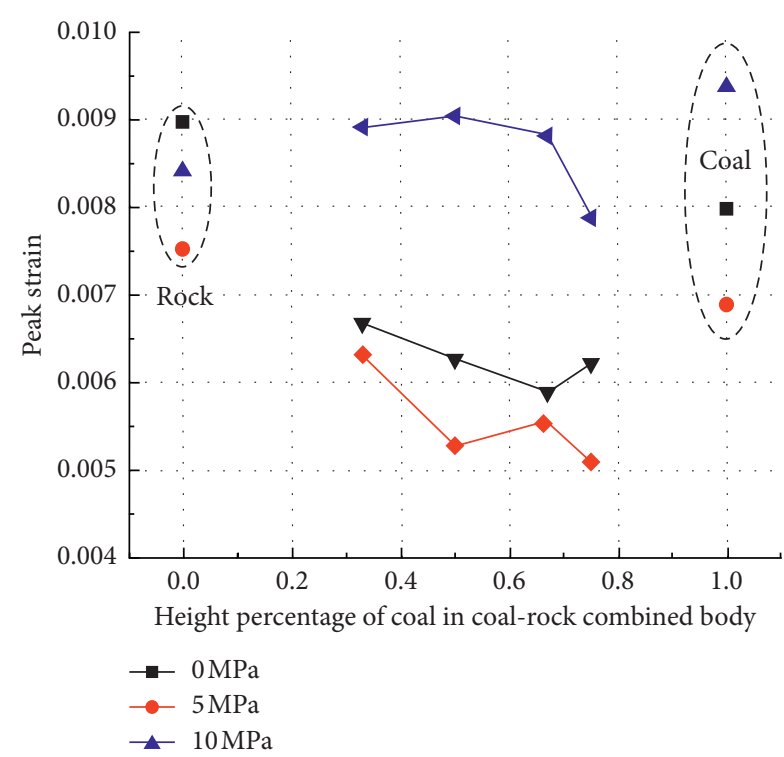

FIGURE 8: Relationship between peak strain and value of coal-rock combination under different confining pressures.

confining pressure increases from $5 \mathrm{MPa}$ to $10 \mathrm{MPa}$, the peak strain increases more, indicating that the coal-rock combination shows more obvious ductility characteristics, under the confining pressure of $10 \mathrm{MPa}$.

The change of elastic modulus of coal-rock combination with $\delta$ value under different confining pressures is shown in Figure 9. The elastic modulus of the coal-rock combination increases with the increase of the confining pressure and has a positive correlation with the confining pressure. Under the same confining pressure, the elastic modulus of coal-rock combination decreases gradually with the increase of $\delta$ value. When the value of $\delta$ is greater than 0.67 , the decrease in the elastic modulus slows down, the elastic modulus of coal is the smallest, and the elastic modulus of rock is the largest.

The strength reduction coefficient of the rock can characterize the brittleness of the rock. According to the calculation formula of the strength reduction coefficient proposed by Peng [41], the brittleness index of the coal-rock combination can be calculated:

$$
D_{s}=\frac{\sigma_{p}-\sigma_{r}}{\sigma_{p}},
$$

where $D_{s}$ is the strength reduction factor of the coal-rock combination and $\sigma_{p}$ and $\sigma_{r}$ are the stress peak and residual strength of the coal-rock combination, respectively, and their values are shown in Table 2.

The relationship between the strength reduction factor of the coal-rock combination and the percentage of coal height to the height of the coal-rock combination $\delta$ and the pressure of the surrounding rock load are calculated (see Figure 10).

When the confining pressure is $0 \mathrm{MPa}$, the $D_{s}$ value of all samples is greater than 0.8 , the brittleness characteristics are obvious, and the $D_{s}$ value of the rock sample is 1 (see Figure $10(\mathrm{a})$ ). When the confining pressure reaches $10 \mathrm{MPa}$, the $D_{s}$ value of coal-rock combination and pure coal samples is less than 0.35 , showing good ductility characteristics. With

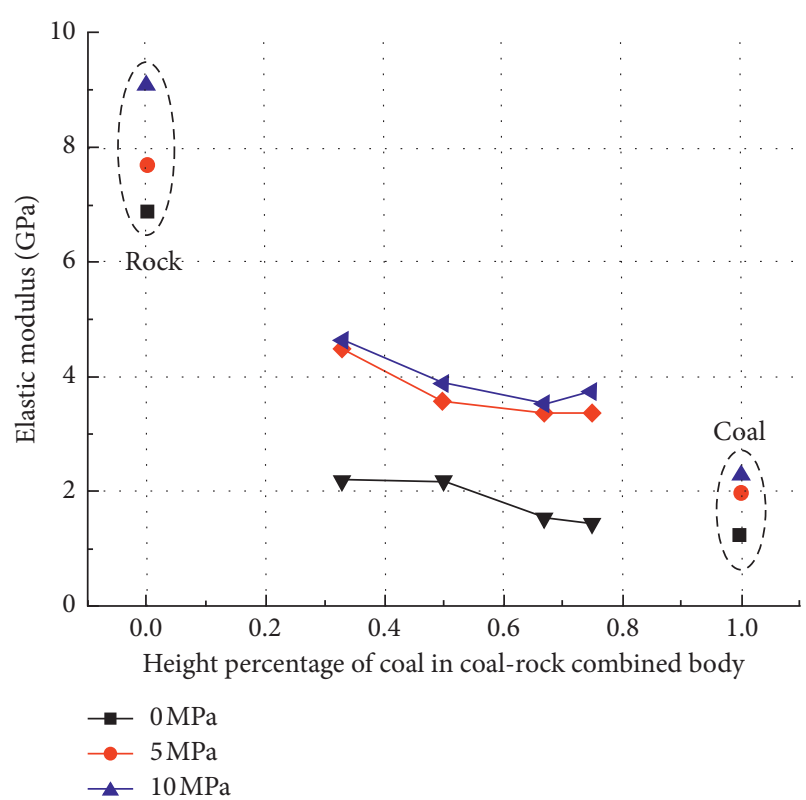

FIgUre 9: Relationship between elastic modulus and $\delta$ value of coal-rock combination under different confining pressures.

the increase of confining pressure, the $D_{s}$ values of the samples decrease approximately linearly. The brittleness of pure rock samples is obvious, with $D_{s}$ values being more than 0.8 . The brittleness of pure coal samples and coal-rock combined samples is small under confining pressure. In the process of increasing the confining pressure, the coal-rock combined samples transform from brittleness to ductility quickly and have better ductility characteristics at low confining pressure. Under uniaxial compression, the strength reduction coefficient of coal-rock combination decreases first with the increase of $\delta$ value and then gradually flattens (see Figure 10(b)). When the confining pressure reaches $5 \mathrm{MPa}$, the overall strength reduction coefficient decreases. When the confining pressure is $10 \mathrm{MPa}$, the strength reduction coefficient shows an approximately horizontal trend. The strength reduction coefficient $D_{s}=0.5$ was used to represent the boundary value between brittleness and ductility of the rock. Under the confining pressure of $10 \mathrm{MPa}$, the coal-rock combination is ductile, and under the confining pressure of $5 \mathrm{MPa}$, the ductility is only present when the value of $\delta$ is greater than 0.33 .

3.2. Deformation Features. Because the coal-rock combination and the coal and rock samples were sealed before the conventional triaxial test, the sample should be completely peeled off after the loading, especially for compressed and brittle coal-containing samples. The failure modes of coal and rock samples and coal-rock combination are shown in Figure 11.

The deformation of rock and coal samples is shown in Figures 11(a) and 11(b). During uniaxial compression, multiple macrocracks appear on the surface of the coal and rock samples, and the macrocracks are mainly vertical tension cracks with a small number of shear cracks, which 


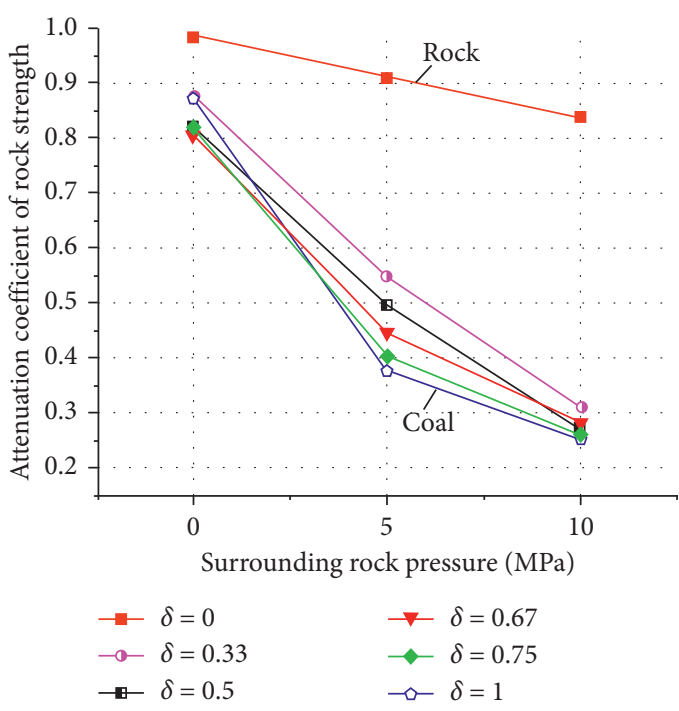

(a)

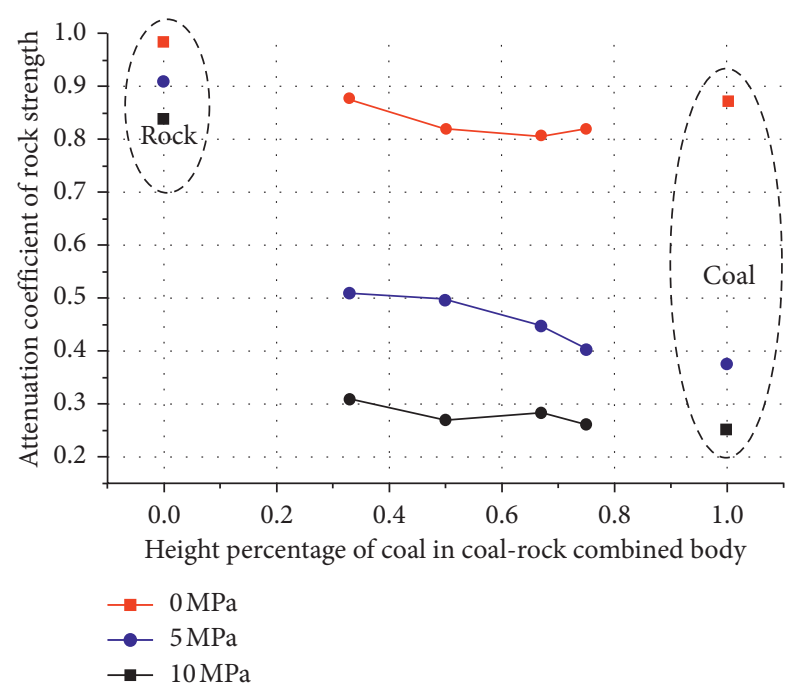

(b)

FIgURE 10: Variation trend of strength reduction coefficient of coal-rock combination. (a) Curve of strength reduction coefficient with confining pressure. (b) Curve of strength reduction coefficient with $\delta$ value.
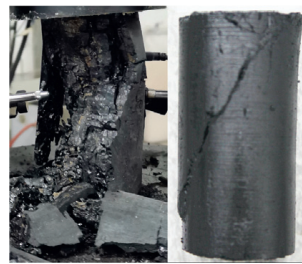

(a)

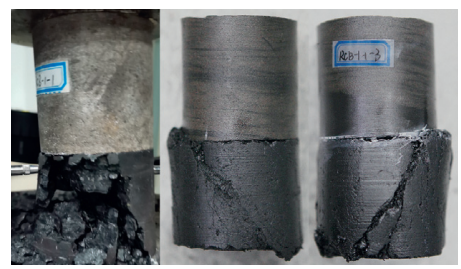

(d)
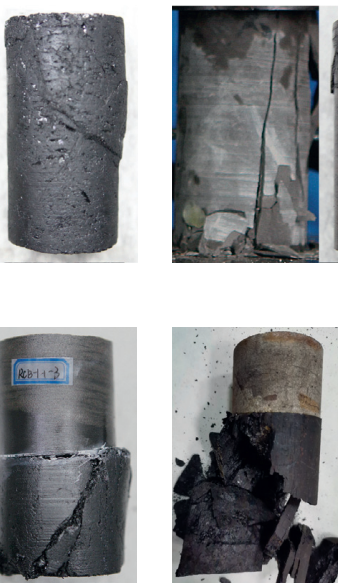

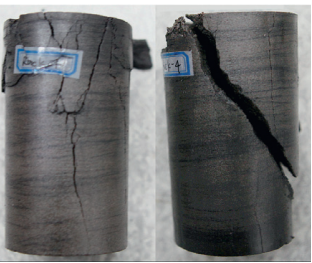

(b)

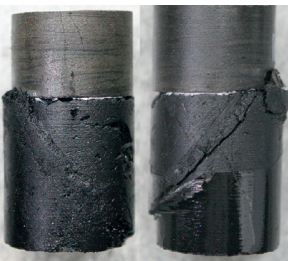

(e)
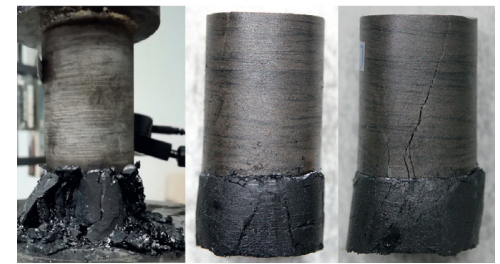

(c)
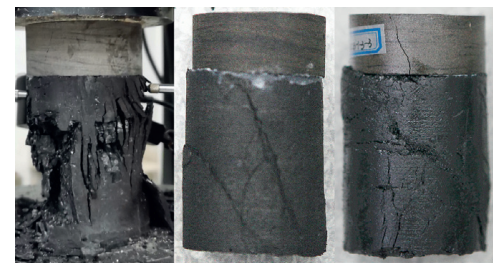

(f)

FIGURE 11: Failure patterns of coal-rock combination and the coal and rock samples under different confining pressures; from left to right, the confining pressures are $0 \mathrm{MPa}, 5 \mathrm{MPa}$, and $10 \mathrm{MPa}$ for each group of pictures. (a) Coal. (b) Rock. (c) RCB-2-1. (d) RCB-1-1. (e) RCB-1-2. (f) RCB-1-3.

indicates that the coal and rock samples are mainly tension cracks. When the confining pressure is $5 \mathrm{MPa}$, the fracture shape of the single coal is oblique shear failure. The average angle between the fracture surface and the axial direction of the sample is $34.8^{\circ}$. The fracture shape of the single rock is mainly oriented to tensile failure, the axial angle of the specimen is small, and the average is $12.3^{\circ}$. The rock failure is accompanied by multiple longitudinal cracks, which are close to the uniaxial compression failure mode. When the confining pressure is $10 \mathrm{MPa}$, the angle between the fracture surface of the coal and the axial direction becomes larger, on average $50.3^{\circ}$, and the breaking angle of the rock is $33.5^{\circ}$.

The failure mode of the RCB-2-1 tests of the coal-rock combination is shown in Figure 11(c); under uniaxial loading, the failure of the coal-rock combined samples is mainly the longitudinal tensile fracture of the coal bodies, accompanied by multiple cracks, and the upper rock part is relatively complete. When the confining pressure is $5 \mathrm{MPa}$, the coal-rock combined samples are mainly shear failure. The average angle between the fracture surface of the fracture surface and the axial direction of the sample is $28.6^{\circ}$, and the rock part is intact. When the confining pressure is $10 \mathrm{MPa}$, the average angle is $30.2^{\circ}$.

The failure mode of the RCB-1-1 and RCB-1-2 tests of coal-rock complex is shown in Figures 11(d) and 11(e), respectively. Under uniaxial loading, the failure of the coalrock combination is mainly the longitudinal tensile fracture of the coal body. There is a macromajor fracture surface in the middle of the coal body, the fracture angle is close to the vertical direction, and the upper rock part is relatively 
complete. When the confining pressure is $5 \mathrm{MPa}$, the coalrock combined samples are mainly shear failure. The average angle between the fracture surface of the fracture surface and the axial direction of the RCB-1-1 sample is $31.2^{\circ}$, while the average angle of the RCB-1-2 is $37.2^{\circ}$ and the rock is partially intact. When the confining pressure is $10 \mathrm{MPa}$, the average angle of the RCB-1-1 sample is $39.2^{\circ}$, while the average angle of the RCB-1-2 is $44.6^{\circ}$.

The failure mode of the RCB-1-3 test for coal-rock combination is shown in Figure 11(f). Under uniaxial loading, the failure is mainly the tensile failure of the coal body and the upper rock part is relatively complete. When the confining pressure is $5 \mathrm{MPa}$, the combination is mainly the shear failure with an average angle of $34.2^{\circ}$ and the rock part is intact. When the confining pressure is $10 \mathrm{MPa}$, the angle is $42.3^{\circ}$ on average.

Take one group $\delta=0.67$ as an example (see Figure 12), at the initial loading, the coal-rock combination is compressed, and the extreme point of volume compression is point $\mathrm{C}$. After point $\mathrm{C}$, the volume of the coal-rock combination changes from decreasing to gradually expanding, indicating that point $C$ is the starting point of the new crack initiation in the coal-rock combination, and point $\mathrm{B}$ corresponding to the stress-strain curve of point $C$ is the critical point of the elastic and plastic phases of coal-rock combination. In the elastic stage, the hoop strain of the coal-rock combination is almost zero. After reaching point $\mathrm{A}$, the circle strain begins to increase at an increasing rate. The increasing starting point A corresponds to point B on the stress-strain curve, which indicates that the plastic deformation is the starting point of the increase of hoop strain. The circle deformation value, volume strain value, and deformation rate in the postpeak phase are much larger than those in the prepeak phase. At the postpeak stage, the coal body in the coal-rock combination has a shear fracture surface. The difference between the lateral deformation of the rock body and the coal body in the coal-rock combination is mainly caused by the shear expansion of the coal body. The lateral deformation of the coal body is far larger than the rock mass.

In summary, it can be considered that the confining pressure has a significant effect on the failure morphology of coal and rock samples and coal-rock combination. The greater the confining pressure, the greater the angle between the fracture surface and the axial direction and the more pronounced the shear failure. Under low confining pressure, the main failure mode is tension failure. Under normal triaxial, the circle deformation value, volume strain value, and deformation rate in the postpeak phase are much greater than in the prepeak phase; shear failure is the main reason for the large lateral deformation of coal body. $\delta$ has a significant impact on the deformation and failure of coal-rock combination. The failure of combination is mainly due to the formation of the main fracture zone in the middle of the coal body.

\section{Strength Characteristics}

4.1. Mohr-Coulomb Criterion. Mohr-Coulomb strength theory has obvious physical background significance. Rock has friction and cohesion. It is a strength theory based on the

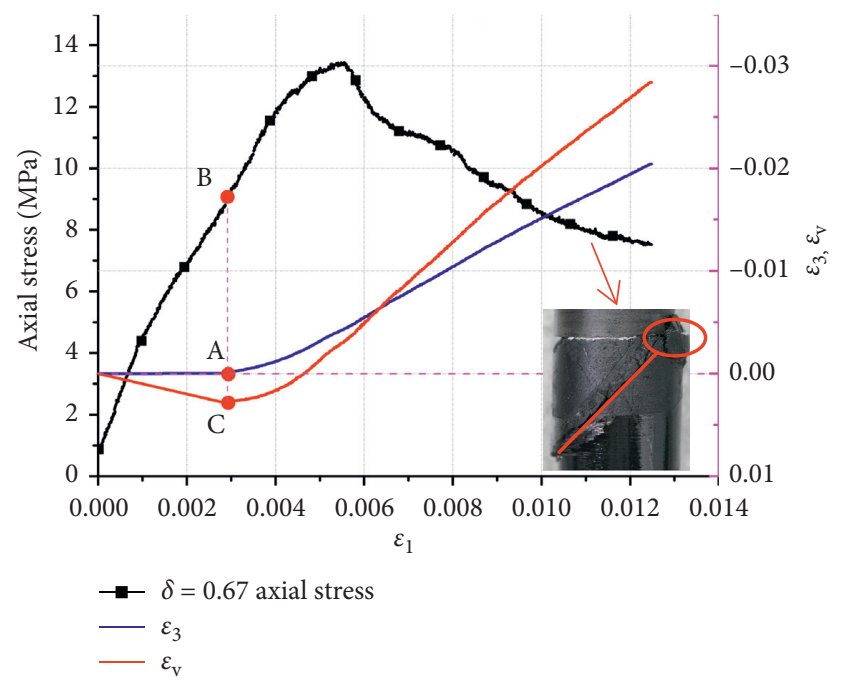

FIgURE 12: The relationship between axial strain-stress and circle and volume strain when confining pressure is $5 \mathrm{MPa}$.

summary of the results of failure tests of rock materials under normal stress. Mohr-Coulomb strength theory holds that the failure of rock is the result of the combined action of shear stress and normal stress on the material's failure surface. In the principal stress space, Coulomb criterion can be expressed as

$$
\sigma_{1}=Q+K \sigma_{3}
$$

where $\sigma_{1}$ is the primary stress of rock failure, $\sigma_{3}$ is the secondary stress of failure, and $Q$ and $K$ are parameters related to the cohesion and internal friction angle of the rock material. $K=\tan ^{2} \psi, Q=2 c \tan \psi, \psi$ is the angle between the rock failure surface and the axial direction of the rock, and $\psi=45^{\circ}-\varphi / 2$.

The Coulomb criterion was used to fit coal-rock combination with different height ratios. The M-C criterion fitting parameters and $R^{2}$ are shown in Table 3 and the fitting results are shown in Figure 13.

4.2. H-B Criterion. The Hoek-Brown criterion [33] (a comprehensive consideration of the effects of multiple factors, which can better reflect the nonlinear failure characteristics of rock masses) is an empirical equation, which usually fits the test data well. The original form of the $\mathrm{H}-\mathrm{B}$ criterion is expressed as

$$
\sigma_{1}=\sigma_{3}+\sigma_{c} \cdot \sqrt{m \cdot \frac{\sigma_{3}}{\sigma_{c}}+1}
$$

In 1992, Hoek et al. [34] improved the H-B strength criterion, called the generalized Hoek-Brown criterion. The GH-B strength criterion increases the coefficient describing the integrity of rocks, which is not only applicable to complete rock samples, but also applicable to rock samples with internal fractures. The generalized $\mathrm{HB}$ criterion is expressed as 
TABLE 3: M-C criterion fitting parameters and $R^{2}$.

\begin{tabular}{lcccccc}
\hline$\delta$ & Fitting curve & $R^{2}$ & Cohesion & The angle of internal friction $(\mathrm{MPa})$ & Theoretical value $\psi$ & Actual value $\psi$ \\
\hline 0 & $\sigma_{1}=51.345+3.761 \sigma_{3}$ & 0.968 & 13.24 & 35.4 & 27.3 & 2.9 \\
0.75 & $\sigma_{1}=5.37+1.277 \sigma_{3}$ & 0.973 & 2.37 & 6.98 & 31.5 & 38.3 \\
0.67 & $\sigma_{1}=5.29+1.848 \sigma_{3}$ & 0.922 & 1.94 & 21.5 & 34.24 & 40.9 \\
0.5 & $\sigma_{1}=6.38+2.158 \sigma_{3}$ & 0.915 & 2.17 & 24.5 & 32.74 & 35.2 \\
0.33 & $\sigma_{1}=8.27+2.418 \sigma_{3}$ & 0.917 & 2.65 & 7.93 & 41.03 \\
1 & $\sigma_{1}=5.81+1.32 \sigma_{3}$ & 0.967 & 2.52 & & 42.5 \\
\hline
\end{tabular}

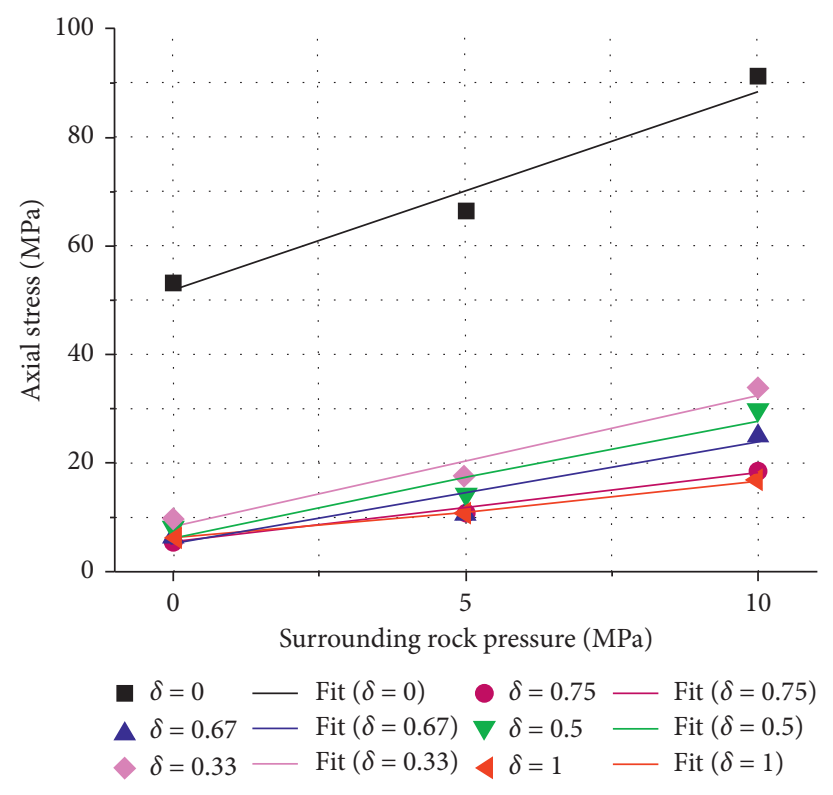

FIGURE 13: Fitting curve of Mohr-Coulomb criterion.

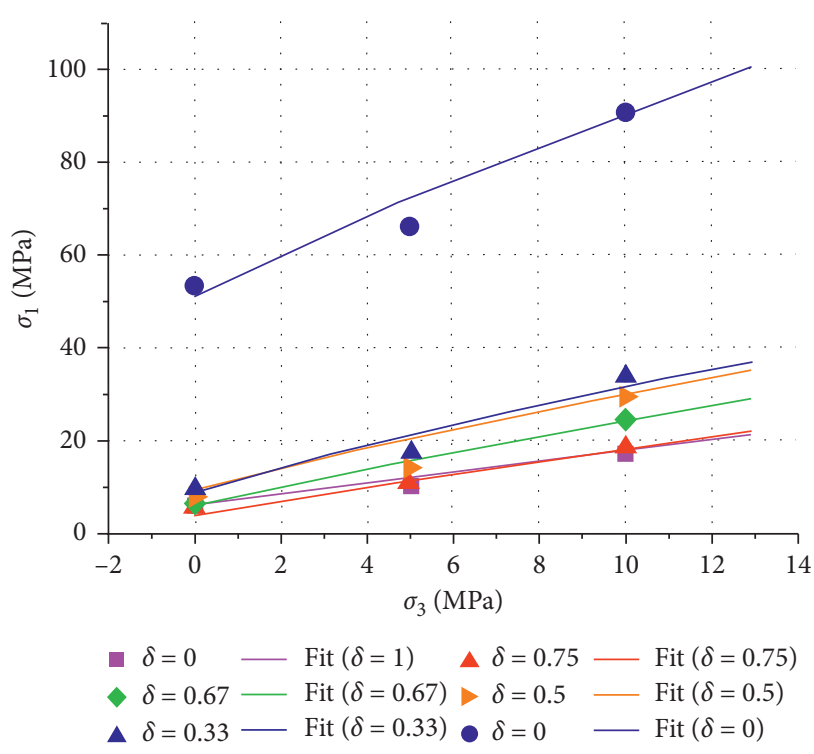

(a)

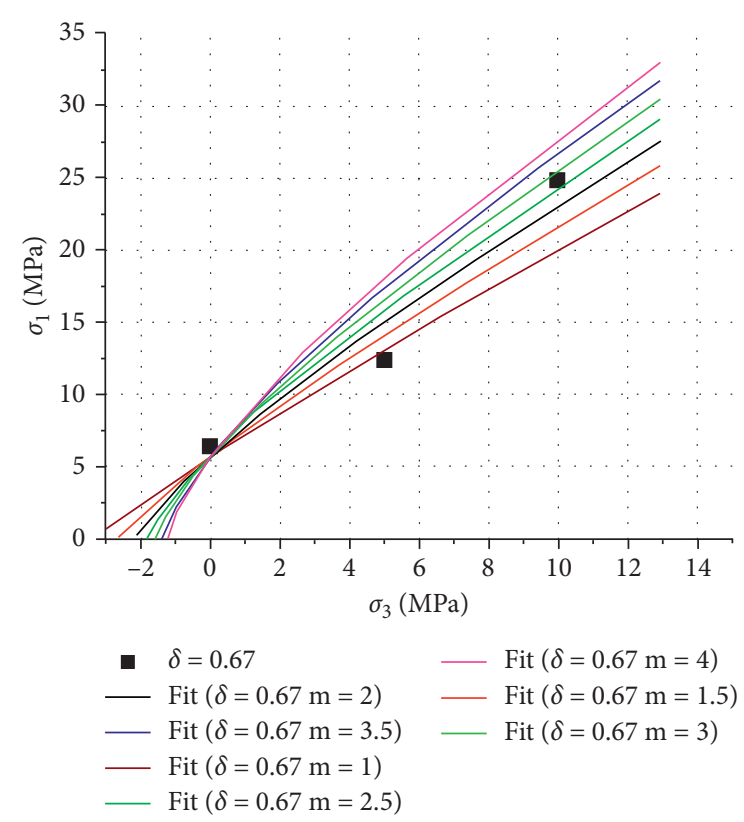

(b)

FIgure 14: The GH-B criterion fitting curve. (a) GH-B criterion fitting curve with different a values. (b) GH-B strength criterion fitting curves with different $\mathrm{m}$ values, when $\delta=0.67$. 
TABLE 4: GH-B criterion fitting parameters and $R^{2}$.

\begin{tabular}{lcccc}
\hline$\delta$ & $R^{2}$ & $m$ & $b$ & $n$ \\
\hline 0 & 0.9144 & 7.09 & 0.927 & 0.51 \\
0.75 & 0.9095 & 1.52 & 0.81 & 0.521 \\
0.67 & 0.9803 & 2.465 & 0.82 & 0.525 \\
0.5 & 0.912 & 2.741 & 0.833 & 0.524 \\
0.33 & 0.924 & 3.674 & 0.88 & 0.541 \\
1 & 0.8803 & 1.1 & 0.88 & 0.53 \\
\hline
\end{tabular}

$$
\sigma_{1}=\sigma_{3}+\sigma_{c} \cdot\left(m \cdot \frac{\sigma_{3}}{\sigma_{c}}+b\right)^{n},
$$

where $\sigma_{c}$ is the uniaxial compressive strength of the rock, $m$ and $b$ are constants about the mechanical properties of the rock, the value of $b$ ranges from 0 to $1, n$ is related to the development degree of internal cracks in the rock, the value is generally $0.5-0.65$, and the value of the block with good quality is 0.5 .

The test data of coal-rock combination and coal and rock samples were fitted using the GH-B criterion (see Figure 14).

The curve has a good fitting effect with experimental results (see Figure $14(\mathrm{a})$ ), $R^{2}$ of the coal-rock combination reaches above 0.9 , and the strength of the coal-rock combination shows an increasing trend with the increase of confining pressure. However, the increase rate gradually slows down. When $\delta=0.5$, the strength of coal-rock combination is the largest, and the rate of strength increase is the same. The values of each parameter and $R^{2}$ are shown in Figure 14(b) and Table 4.

Among them, the $m$ value of rock and coal is up to 7.09 and 1.1, and the $m$ value of coal-rock combination is between them. The values of $n$ that characterize the internal voids and fractures of the rock are between 0.5 and 0.54 . Take $\delta=0.67$ as an example, take $n$ and $b$ as fixed values, and change the value of $m$. When $m$ is small value, the absolute value of the intersection between the curve and the abscissa is larger, and the tensile strength of the coal-rock combination is larger. When the $m$ value is $2-3$, there is a better fitting trend.

\section{Summary}

In this paper, the conventional triaxial tests were performed on the combination of number 3 coal seam and roof of Zhangcun Coal Mine with different height ratios and confining pressures. The peak stress, elastic modulus, and strength reduction coefficient of coal-rock assembly are negatively related to the proportion of coal height and positively related to the confining pressure.

Under uniaxial compression, the coal and rock samples and coal-rock combined samples are mainly tensile failures. The forms are mainly inclined shear failures, under conventional triaxial loading. The angle between the fracture surface and the axial direction is between $30^{\circ}$ and $40^{\circ}$, the $\mathrm{M}-\mathrm{C}$ criterion is used for fitting, and the calculated fracture angle is approximately equal to the actual one.

The higher the confining pressure, the larger the angle between the fracture surface and the axial direction and the more obvious the shear failure characteristics. The circumferential deformation value, volume strain value, and deformation rate in the postpeak phase are much greater than in the prepeak phase; shear failure is the main reason for the large lateral deformation of coal body.

Using different strength criteria to fit experimental data of coal and rock samples and coal-rock combination, the fitted $R^{2}$ values are all above 0.9 , and the fitting effect is good.

\section{Data Availability}

The data used to support the findings of this study are included within the supplementary information files.

\section{Conflicts of Interest}

The authors declare no conflicts of interest.

\section{Authors' Contributions}

Tuo Wang and Zhanguo Ma conceived and established the experimental system; Gong Peng guided thesis writing; Shixing Cheng and Ning Li analyzed the data; Tuo Wang wrote the paper.

\section{Acknowledgments}

This research was funded by the National Natural Science Foundation of China, under Grant nos. 51674250 and 51804302, China Postdoctoral Science Foundation, under Grant no. 2019M652018, Major Program of National Natural Science Foundation of China, under Grant nos. 51734009 and 51323004, and National Key Research and Development Projects of China, under Grant no. 2019YFC1904304.

\section{Supplementary Materials}

The supplementary materials include the test data supporting the manuscript. (Supplementary Materials)

\section{References}

[1] S.-Q. Yang, M. Chen, H.-W. Jing, K.-F. Chen, and B. Meng, “A case study on large deformation failure mechanism of deep soft rock roadway in xin'An coal mine, China," Engineering Geology, vol. 217, pp. 89-101, 2017.

[2] Y. Lu, L. Wang, and B. Zhang, "An experimental study of a yielding support for roadways constructed in deep broken soft rock under high stress," Mining Science \& Technology, vol. 21, pp. 89-94, 2011.

[3] B. Shen, "Coal mine roadway stability in soft rock: a case study," Rock Mechanics and Rock Engineering, vol. 47, no. 6, pp. 2225-2238, 2014.

[4] R. Yang, Y. Li, D. Guo, L. Yao, T. Yang, and T. Li, "Failure mechanism and control technology of water-immersed roadway in high-stress and soft rock in a deep mine," International Journal of Mining Science and Technology, vol. 27, no. 2, pp. 245-252, 2017.

[5] Y. Yuan, Y. Zhu, W. Wang, and W. Yu, "Failure mechanism of Mesozoic soft rock roadway in Shajihai coal mine and its 
surrounding rock control," International Journal of Mining Science and Technology, vol. 24, no. 6, pp. 853-858, 2014.

[6] J. C. Chang and G. X. Xie, "Investigation on deformation and failure characteristics and stability control of soft rock roadway surrounding rock in deep coal mine," Advanced Materials Research, vol. 255-260, pp. 3711-3716, 2011.

[7] Z. Yin, Z. Hu, Z. Wei et al., "Assessment of blasting-induced ground vibration in an open-pit mine under different rock properties," Advances in Civil Engineering, vol. 2018, Article ID 4603687, 10 pages, 2018.

[8] Q. Liu, K. Liu, J. Zhu et al., "Study on mechanical properties of raw coal under high stress triaxial compression," Journal of Rock Mechanics and Engineering, vol. 33, pp. 24-34, 2014.

[9] S.-Q. Yang and Q. Sheng, "Experimental study on deformation, peak strength and crack damage behavior of hollow sandstone under conventional triaxial compression," Engineering Geology, vol. 213, pp. 11-24, 2016.

[10] S.-Q. Yang and Q. Sheng, "Strength and deformation behavior of red sandstone under multi-stage triaxial compression," Canadian Geotechnical Journal, vol. 49, no. 6, pp. 694-709, 2012.

[11] M. Mukherjee, G. D. Nguyen, A. Mir et al., "Capturing pressure- and rate-dependent behaviour of rocks using a new damage-plasticity model," International Journal of Impact Engineering, vol. 110, pp. 208-218, 2017.

[12] C. Lu, L. dou, X. Wu, S. Zhang, and Z. Mou, "Strength weakening of coal mine rock burst," Journal of Engineering Science, vol. 29, pp. 1074-1078, 2007.

[13] T. Bruning, M. Karakus, G. D. Nguyen, and D. Goodchild, "An experimental and theoretical stress-strain-damage correlation procedure for constitutive modelling of granite," International Journal of Rock Mechanics and Mining Sciences, vol. 116, pp. 1-12, 2019.

[14] B. Thomas, K. Murat, G. D. Nguyen, and G. David, "Experimental study on the damage evolution of brittle rock under triaxial confinement with full circumferential strain control," Rock Mechanics \& Rock Engineering, vol. 51, pp. 3321-3341, 2018.

[15] T. Bruning, M. Karakus, G. D. Nguyen, and D. Goodchild, "An experimental and theoretical stress-strain-damage correlation procedure for constitutive modelling of granite," International Journal of Rock Mechanics and Mining Sciences, vol. 116, pp. 1-12, 2019.

[16] Y. Zhao, S. Gong, X. Hao, Y. Peng, and Y. Jiang, "Effects of loading rate and bedding on the dynamic fracture toughness of coal: laboratory experiments," Engineering Fracture Mechanics, 2017.

[17] G. Xie, Z. Yin, L. Wang, Z. Hu, and C. Zhu, "Effects of gas pressure on the failure characteristics of coal," Rock Mechanics and Rock Engineering, vol. 50, no. 7, pp. 1711-1723, 2017.

[18] Z. Zhou, L. Chen, X. Cai, B. Shen, J. Zhou, and K. Du, "Experimental investigation of the progressive failure of multiple pillar-roof system," Rock Mechanics \& Rock Engineering, vol. 51, pp. 1629-1636, 2018.

[19] Q. Bai, M. Tibbo, M. H. B. Nasseri, and R. P. Young, "True triaxial experimental investigation of rock response around the mine-by tunnel under an in situ 3D stress path," Rock Mechanics and Rock Engineering, vol. 52, pp. 3971-3986, 2019.

[20] L. U. Qun, B. Zhang, and L. Wang, "Experimental study on strength and deformation performance of fiber recycled concrete under conventional triaxial compression," World Earthquake Engineering, vol. 31, pp. 243-250, 2015.

[21] D. Li, S. Zhi, X. Tao, X. Li, and P. G. Ranjith, "Energy evolution characteristics of hard rock during triaxial failure with different loading and unloading paths," Engineering Geology, vol. 228, 2017.

[22] D. Unteregger, B. Fuchs, and G. Hofstetter, "A damage plasticity model for different types of intact rock," International Journal of Rock Mechanics and Mining Sciences, vol. 80, pp. 402-411, 2015.

[23] J. Bai and W. Li, "Determination of coal-rock interface strength by laboratory direct shear tests under constant normal load," International Journal of Rock Mechanics \& Mining Sciences, vol. 77, pp. 60-67, 2015.

[24] J. Peng, G. Rong, M. Cai, X. Wang, and C. Zhou, "An empirical failure criterion for intact rocks," Rock Mechanics and Rock Engineering, vol. 47, no. 2, pp. 347-356, 2014.

[25] H. Zhang, H. Li, T. Zhang, Q. Wang, and T. Guo, "Research and engineering application of high pre-stressed resistance enhancement large deformation bolt in deep soft rock roadway," Meitan Xuebao/Journal of the China Coal Society, vol. 44, pp. 409-418, 2019.

[26] Z. Yin, W. Chen, H. Hao et al., "Dynamic compressive test of gas-containing coal using a modified split Hopkinson pressure bar system," Rock Mechanics and Rock Engineering, vol. 53, pp. 815-829, 2020.

[27] J. Zuo, C. Yan, J. Zhang, J. Wang et al., "Failure behavior and strength characteristics of coal rock combination under different confining pressures," Journal of Coal Industry, vol. 41, pp. 2706-2713, 2016.

[28] J. Zuo, H. Xie, A. Wu et al., "Study on failure mechanism and mechanical properties of deep coal rock monomers and combinations," Journal of Rock Mechanics and Engineering, vol. 30, pp. 84-92, 2011.

[29] Y. L. Tan, X. S. Liu, B. Shen, J. G. Ning, and Q. H. Gu, "New approaches to testing and evaluating the impact capability of coal seam with hard roof and/or floor in coal mines," Geomechanics and Engineering, vol. 14, pp. 367-376, 2018.

[30] B. Huang and J. Liu, "The effect of loading rate on the behavior of samples composed of coal and rock," International Journal of Rock Mechanics and Mining Sciences, vol. 61, pp. 23-30, 2013.

[31] C. Lu, L. Dou, X. Wu, Z. Mou, and G. Chen, "Experimental and empirical research on frequency-spectrum evolvement rule of rockburst precursory microseismic signals of coalrock," Chinese Journal of Rock Mechanics \& Engineering, vol. 27, pp. 519-525, 2008.

[32] T. Wang, Y. Jiang, S. Zhan, and C. Wang, "Frictional sliding tests on combined coal-rock samples," Journal of Rock Mechanics and Geotechnical Engineering, vol. 6, no. 3, pp. 280286, 2014.

[33] E. Hoek and Brown, "Empirical strength criterion for rock masses," Geotechnical Engineering, vol. 18, p. 23, 1981.

[34] E. Hoek, D. Wood, and S. Shah, "Modified Hoek-Brown failure criterion for jointed rock masses," International Journal of Rock Mechanics and Mining Sciences, vol. 30, p. A215, 1993.

[35] M. You, "True-triaxial strength criteria for rock," International Journal of Rock Mechanics and Mining Sciences, vol. 46, no. 1, pp. 115-127, 2009.

[36] J. Zuo, H. song, C. Yan et al., "Post peak progressive failure characteristics and nonlinear model of coal rock assemblages," Journal of Coal Industry, vol. 43, pp. 3265-3272, 2018.

[37] K. Franklin and S. Zhang, "Recommended method for determining rock stress by the Committee of test methods of the international society of rock mechanics," Journal of Rock Mechanics and Engineering, vol. 7, pp. 69-100, 1988. 
[38] J. F. Labuz and J. M. Bridell, "Reducing frictional constraint in compression testing through lubrication," International Journal of Rock Mechanics and Mining Sciences \& Geomechanics Abstracts, vol. 30, no. 4, pp. 451-455, 1993.

[39] S. Yang, C. Su, and W. Xu, "Experimental and theoretical research on size effect of rock materials," Engineering $\mathrm{Me}$ chanics, vol. 22, pp. 112-118, 2005.

[40] B. Liu and J. Zhang, "Size effect of rock compressive strength," Journal of Rock Mechanics and Engineering, vol. 17, pp. 611614, 1998.

[41] J. Peng, R. Guan, M. Cai, and K. Peng, "Determining residual strength of rock based on a brittle index," Geotechnical Mechanics, vol. 36, pp. 403-408, 2015. 